\title{
Predictors of intra-abdominal adhesions
}

\author{
Fady Shehata • Afsoon Zarei • Einat Shalom-Paz • \\ Togas Tulandi
}

Received: 2 February 2011 /Accepted: 24 February 2011 / Published online: 11 March 2011

(C) Springer-Verlag 2011

\begin{abstract}
The objective of this study is to evaluate the prevalence and predicting factors for intra-abdominal adhesions among 1,050 consecutive cases of laparoscopy. This study is designed as a retrospective cohort study. Multivariate linear regression model was constructed to determine factors associated with increased intra-abdominal adhesions including age, number of previous abdominal operations, and endometriosis. Adhesions were graded using a modified (ASRM) classification for adnexal adhesions. Factors affecting the development of intraabdominal adhesions were number of previous abdominal operations $(P<0.0001,95 \%$ CI $0.18-0.30)$ and degree of endometriosis $(P<0.0001,95 \%$ CI $0.25-0.35)$. Endometriosis had more influence on adhesion formation than number of previous operations as demonstrated by the standardized coefficients beta in endometriosis $(0.32)$ versus previous abdominal operations (0.21). Age, BMI, and PID were not associated with increased abdominal adhesions. Endometriosis and abdominal operations play an important role in development of intra-abdominal adhesions. However, endometriosis has more influence on adhesions than previous operations.
\end{abstract}

F. Shehata $(\varangle) \cdot$ E. Shalom-Paz $\cdot$ T. Tulandi Department of Obstetrics and Gynecology, McGill University Health Center, 687 Pine Avenue West,

Montreal, QC, Canada H3A 1A1

e-mail: fady.shehata@mail.mcgill.ca

\section{A. Zarei}

Department of Obstetrics and Gynecology,

Shiraz University of Medical Sciences,

Shiraz, Iran
Keywords Adhesions · Endometriosis · Laparotomy · Abdominal surgery

\section{Background}

Adhesions are fibrous tissues formed as a response to injury during surgical operations. Intra-abdominal adhesions are the most common complication of abdominal operations [1]. Adhesions might cause pelvic pain, infertility, and small bowel obstruction (SBO). In fact, intra-abdominal adhesions are the most common cause of SBO [2-6]. These complications may occur shortly or many years after the operations [7].

Factors contributing to intra-abdominal adhesions include abdominal operations (either laparotomy or laparoscopy), endometriosis, or intra-abdominal infection. Studies of adhesions related readmission showed that $30 \%$ of patients would be readmitted at least once after an abdominal surgery $[8,9]$. In neonates, the percentage was $8.3 \%$ [10]. Although causes of adhesions are well established, the extent and association between these predisposing factors and the formation of adhesions remain unclear.

The purpose of our study was to evaluate predicting factors of intra-abdominal adhesions in a large population of women who underwent a laparoscopy by a single surgeon.

\section{Methods}

We evaluated 1,050 consecutive cases of laparoscopy between May 1982 and August 2009. All laparoscopies were 
performed by the senior author in two McGill University teaching hospitals, the Royal Victoria Hospital and the Sir Mortimer B. Davis, Jewish General Hospital. The study was approved by the director of professional services.

Data were collected directly from patients' charts by two physicians (FS and AZ) and entered in a Microsoft Excel database. All data were obtained from hospital records and cross-checked with office files.

Variables included patient's demography, number and description of previous abdominal operations, history and classification of endometriosis, presence or absence of pelvic inflammatory disease, main presenting symptom, type of operation, and postoperative diagnosis. The senior author routinely drew a diagram using a modified American Society of Reproductive Medicine (ASRM) classification for adnexal adhesions after each surgical procedure. Adhesions, if any, were graded as 0 (no adhesions), 1 (mild), 2 (moderate), and 3 (severe). Endometriosis was classified using ASRM classification for endometriosis as 0 (no endometriosis), 1 (minimal), 2 (mild), 3 (moderate), and 4 (severe).

\section{Statistical analysis}

Normality of data distribution was examined using ShapiroWilk test. We used multiple linear logistic regression analysis to construct a model for predicting the presence of intraabdominal adhesions (dependant variable) from other parameters (independent variables). ANOVA was used to determine the usefulness of our model variables to predict the outcome $(P<0.0001$, degrees of freedom $=278)$. The differences were considered statistically significant if $P$ was less than 0.05 .

\section{Findings}

The mean age and the body mass index of the patients were $38.6 \pm 9.2$ and $24.0 \pm 4.9$ years, respectively. Among

Table 1 Distribution of patients by number of previous abdominal operation

\begin{tabular}{ccc}
\hline No. of previous surgery & No. of patients & Percentage (\%) \\
\hline 0 & 559 & 53.2 \\
1 & 283 & 27.0 \\
2 & 131 & 12.5 \\
3 & 44 & 4.2 \\
4 & 23 & 2.2 \\
5 & 6 & 0.6 \\
6 & 4 & 0.4 \\
Total & 1,050 & 100.0 \\
\hline
\end{tabular}

Table 2 Indications for surgery in study population

\begin{tabular}{lc}
\hline Indications for surgery & Total \\
\hline Ovarian cyst & 282 \\
Fibroids & 220 \\
Infertility & 171 \\
Endometriosis & 117 \\
Menorrhagia & 74 \\
Others & 62 \\
Tubal condition & 34 \\
Cancer & 34 \\
Pelvic pain & 22 \\
\hline
\end{tabular}

1,050 women, 559 women $(53.2 \%)$ had had no previous abdominal operation, $27 \%$ had one previous abdominal surgery, and the remainders had two or more abdominal operations (Table 1). Intra-abdominal adhesions were found in 343 patients (32.6\%). These included women who had never undergone any previous abdominal surgery, women who had had previous surgeries and/or endometriosis. Indications for surgery included ovarian cyst removal (27.8\%), fibroids (21.7\%), and infertility (16.8\%, Table 2).

In a subgroup of patients (subgroup A) who had at least one previous surgery and no endometriosis $(n=352)$, adhesions were found in 140 women $(40 \%)$. In another subgroup of patients (subgroup B) who had history of endometriosis and no previous operations $(n=138)$, adhesions were found in 61 women $(44.2 \%)$. In a third subgroup of patients (subgroup C) who had never had any operations, or endometriosis $(n=413)$, adhesions were found in 60 women (14.5\%, Fig. 1).

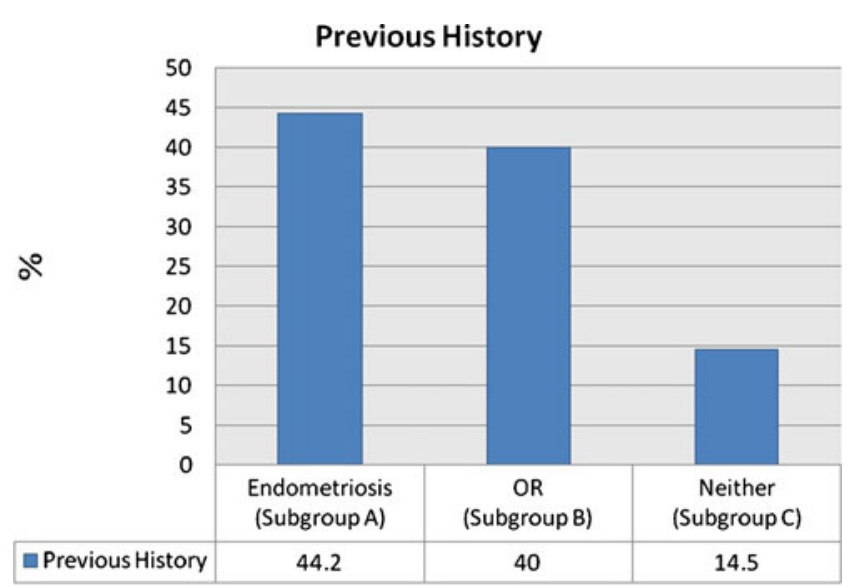

Fig. 1 Prevalence of adhesions in patients with endometriosis, previous abdominal surgery, or neither 
Table 3 Multiple linear regression analysis for predictors of intra-abdominal adhesions using age, history of PID, endometriosis, and previous abdominal operation

\begin{tabular}{lllllr}
\hline & B & SE & Beta & $P$ value & \multicolumn{1}{c}{$95 \%$ CI } \\
\hline Age & 0.005 & 0.004 & 0.039 & NS & $(0.00-0.01)$ \\
PID & 0.045 & 0.240 & 0.005 & NS & $(-0.43-0.52)$ \\
Endometriosis & 0.298 & 0.027 & 0.325 & $<0.0001$ & $(0.25-0.35)$ \\
Previous abdominal operation & 0.238 & 0.032 & 0.217 & $<0.0001$ & $(0.18-0.30)$ \\
\hline
\end{tabular}

$N S$ not significant

adhesions. However, it is possible that some patients in our

To evaluate the relationship between the intra-abdominal adhesions (dependent variable) and independent variables, we constructed a multiple linear regression model (Table 3). Both endometriosis and history of previous abdominal operation were significantly associated with the presence of intra-abdominal adhesions $(P<0.0001)$. We then examined the standard coefficient beta to determine the variable with more influence. Endometriosis had a stronger influential role than previous abdominal operation (beta 0.27 and 0.17 ) respectively.

We also evaluated a subgroup of patients who had had only one previous laparoscopy $(n=107)$ or laparotomy $(n=$ 59) and another subgroup of patients who had had clean surgery (not involving intestine, $n=188$ ) or dirty surgery (involving intestine, $n=59$ ) (Table 4). Patients who had had a laparotomy were more likely to have intra-abdominal adhesions than those who had had a previous laparoscopy $(P<0.0001,95 \% \mathrm{CI}=1.02-1.99)$. The type of operation (whether clean or dirty) did not affect adhesion formation.

\section{Conclusions}

Intra-abdominal adhesions are a major complication of abdominal operations. The presence of adhesions leads to increased operating time [11-13], increased risk of abdominal injury in subsequent surgery [14], and increased health care expenditure to treat subsequent complications [15].

Our results show that both previous history of endometriosis and previous abdominal operations increase the risk of developing adhesions. In addition, endometriosis plays a more influential role than number of previous abdominal operations. Of interest, history of pelvic inflammatory disease (PID) did not appear to increase intra-abdominal population had had subclinical PID which was undiagnosed and not reported in the charts.

We found the prevalence of adhesions in patients who only had previous surgeries to be $40 \%$. In a postmortem study, Weibel and Majno reported a $67 \%$ adhesion rate in individuals who had a history of previous operations [16]. Dubuisson et al. in 2010 showed $21.1 \%$ adhesions rate in a similar population [17]. Whether the patients in their study had endometriosis is not clear. In our study the influential role of endometriosis was reflected in the highest adhesions rate.

In agreement with previous studies, we found that patients who had a previous laparotomy are more likely to develop adhesions than patients with previous laparoscopies. In a randomised trial, Lundorff et al. studied 105 patients who had ectopic pregnancies and were randomised to surgery by either laparoscopy or laparotomy [18]. They found that the laparotomy group had significantly higher density of adhesions than the laparoscopy group [18].

Both types of operations (clean or dirty) were not found to increase the density of adhesions. This may suggest that bowel injury during abdominal operations does not increase the risk of adhesions. This information is useful in consulting patients following gynecological operations complicated with bowel injuries. The limitations of our study included lack of information regarding the type of incision in previous operations and of adhesion site in the laparoscopy report.

We conclude that the risk factors of intra-abdominal adhesions are mainly endometriosis and the number of previous abdominal operations. The incidence of adhesions in patients with previous history of endometriosis is the highest. Patients with previous laparotomy are more likely to develop adhesions than laparoscopy.

Table 4 Multiple regression analysis for predictors of intra-abdominal adhesions in a subgroup of patients with only one previous abdominal operation by laparoscopy or laparotomy, and clean versus dirty operations

\begin{tabular}{llllrr}
\hline & B & SE & Beta & P value & $95 \%$ CI \\
\hline Laparoscopy versus laparotomy & 1.23 & 0.22 & 0.47 & $<0.0001$ & $(0.79-1.68)$ \\
Clean versus dirty & 0.03 & 0.44 & -0.01 & NS & $(-0.91-0.84)$ \\
\hline
\end{tabular}

NS not significant 


\section{Acknowledgments None}

Declaration of interest The authors report no conflicts of interest. The authors alone are responsible for the content and writing of the paper.

\section{References}

1. DeWilde RL, Trew G (2007) Postoperative abdominal adhesions and their prevention in gynaecological surgery. Expert consensus position. Part 2-steps to reduce adhesions. Gynecol Surg 4 (4):243-253

2. Krebs HB, Goplerud DR (1987) Mechanical intestinal obstruction in patients with gynecologic disease: a review of 368 patients. Am J Obstet Gynecol 157(3):577-583

3. Perry JF Jr, Smith GA, Yonehiro EG (1955) Intestinal obstruction caused by adhesions: a review of 388 cases. Ann Surg 142 (5):810-816

4. Ratcliff JB, Kapernick P, Brooks GG, Dunnihoo DR (1983) Small bowel obstruction and previous gynecologic surgery. South Med J 76(11):1349-1350, 1360

5. Nappi C, Di Spiezio SA, Greco E, Guida M, Bettocchi S, Bifulco G (2007) Prevention of adhesions in gynaecological endoscopy. Hum Reprod Update 13(4):379-394. doi:10.1093/humupd/dm1061

6. Vrijland WW, Jeekel J, van Geldorp HJ, Swank DJ, Bonjer HJ (2003) Abdominal adhesions: intestinal obstruction, pain, and infertility. Surg Endosc 17(7):1017-1022. doi:10.1007/s00464002-9208-9

7. Al-Sunaidi M, Tulandi T (2006) Adhesion-related bowel obstruction after hysterectomy for benign conditions. Obstet Gynecol 108 (5):1162-1166. doi:10.1097/01.AOG.0000239098.33320.c4

8. Ellis H, Moran BJ, Thompson JN, Parker MC, Wilson MS, Menzies D, McGuire A, Lower AM, Hawthorn RJ, O'Brien F, Buchan S, Crowe AM (1999) Adhesion-related hospital readmissions after abdominal and pelvic surgery: a retrospective cohort study. Lancet 353(9163):1476-1480. doi:10.1016/S01406736(98)09337-4

9. Parker MC, Ellis H, Moran BJ, Thompson JN, Wilson MS, Menzies D, McGuire A, Lower AM, Hawthorn RJ, O'Briena F, Buchan S, Crowe AM (2001) Postoperative adhesions: ten-year follow-up of 12,584 patients undergoing lower abdominal surgery. Dis Colon Rectum 44(6):822-829, discussion 829-830

10. Wilkins BM, Spitz L (1986) Incidence of postoperative adhesion obstruction following neonatal laparotomy. Br J Surg 73(9):762764

11. Sot KC, Davidson T, Parker M (1998) Intestinal obstruction in patients with gynaecological malignancies. Ann Acad Med 17:7275

12. Beck DE, Ferguson MA, Opelka FG, Fleshman JW, Gervaz P, Wexner SD (2000) Effect of previous surgery on abdominal opening time. Dis Colon Rectum 43(12):1749-1753

13. Coleman MG, McLain AD, Moran BJ (2000) Impact of previous surgery on time taken for incision and division of adhesions during laparotomy. Dis Colon Rectum 43(9):1297-1299

14. Van Der Krabben AA, Dijkstra FR, Nieuwenhuijzen M, Reijnen MMPJ, Schaapveld M, Van Goor H (2000) Morbidity and mortality of inadvertent enterotomy during adhesiotomy. $\mathrm{Br} \mathrm{J}$ Surg 87(4):467-471

15. Al-Fozan H, Dufort J, Kaplow M, Tulandi T (2003) Cost analysis of adhesion-related admissions in a Canadian teaching hospital. Int J Gynaecol Obstet 82(2):227-228

16. Weibel MA, Majno G (1973) Peritoneal adhesions and their relation to abdominal surgery. A postmortem study. Am J Surg 126(3):345-353

17. Dubuisson J, Botchorishvili R, Perrette S, Bourdel N, Jardon K, Rabischong B, Canis M, Mage G (2010) Incidence of intraabdominal adhesions in a continuous series of 1000 laparoscopic procedures. Am J Obstet Gynecol 203(2):111.e111-111.e113. doi:10.1016/j.ajog.2010.03.031

18. Lundorff P, Hahlin M, Kallfelt B, Thorburn J, Lindblom B (1991) Adhesion formation after laparoscopic surgery in tubal pregnancy: a randomized trial versus laparotomy. Fertil Steril 55(5):911-915 